\title{
MODELING OF THE TENSION AND COMPRESSION BEHAVIOR OF SINTERED 316L USING MICRO COMPUTED TOMOGRAPHY
}

\author{
Michał DOROSZKO*, Andrzej SEWERYN* \\ *Faculty of Mechanical Engineering, Department of Mechanics and Applied Computer Science, Bialystok University of Technology, \\ ul. Wiejska 45C, 15-351 Białystok, Poland \\ m.doroszko@doktoranci.pb.edu.pl, a.seweryn@pb.edu.pl
}

received 3 March 2015, revised 17 July 2015, accepted 20 July 2015

\begin{abstract}
This paper describes the method of numerical modeling of the tension and compression behavior of sintered $316 \mathrm{~L}$. In order to take into account the shape of the mesostructures of materials in the numerical modeling, X-ray microtomography was used. Based on the micro-CT images, three-dimensional geometrical models mapped shapes of the porosity were generated. To the numerical calculations was used finite element method. Based on the received stress and strain fields was described the mechanism of deformation of the materials until fracture. The influence of material discontinuities at the mesoscopic scale on macromechanical properties of the porous materials was investigated.
\end{abstract}

Key words: Finite Element Method, X-Ray Microtomography, Porous Materials, Mechanical Properties, Plasticity

\section{INTRODUCTION}

Austenitic steel $316 \mathrm{~L}$ is one of the most commonly used biomaterials for internal fixation devices due to its advantageous combination of mechanical properties, corrosion resistance and cost effectiveness when compared to other metallic implant materials (Disegi and Eschbach, 2000).

Modeling and simulation methods have made significant contributions to understanding of the mechanical properties of cellular materials in conjunction with their structures (Ashby et al., 2000; Rammerstorfer et al., 2002). Determination of the relationships between the structure and properties of cellular materials is a difficult issue because of the complex spatial structure (Kujime et al., 2007; Maruyama et al., 2006). Until recently, in most three-dimensional FEM models were used the simplified control volumes (De Giorgi et al., 2010; Marcadon, 2011; Nammi et al., 2010). Such analyses did not include the effect of the complex geometry which is required for the proper calculation of stress and strain values in the material (Michailidis et al., 2010). Irregular morphology of pores in sintered 316L prevents the use of the geometries simplifications.

Recent researches into cellular materials has been using models mapping the realistic geometries. The most popular method of obtaining cross sections is X-ray computed microtomography (micro-CT). The largest number of works describe the FEM modeling of the strength properties of cellular metallic materials, such as Al open-cell sponge and close-cell foam (Veyhl et al., 2011), porous Al (Michailidis et al., 2010), Ni-foam (Michailidis, 2011), and sintered metal fibers (Veyhl et al., 2013).

This paper presents numerical modeling (FEM) of the tension and compression behavior of porous sintered $316 \mathrm{~L}$. Based on high resolution micro-CT images, the structures of the porous materials (on a mesoscale) were mapped as 3D models. On the basis of numerical results, the effect of sintered porous mesostructures on their mechanical properties was described.

\section{DETERMINATION OF THE TRUE STRESS-STRAIN CURVE OF THE SOLID 316L}

Modeling of the tensile and compression behavior of porous $316 \mathrm{~L}$ required the determination of the true stress-strain curve of the solid 316L (Sandvik Sanmac 316L). For this reason was carried out the monotonic axial tensile test of the solid material.

In the experiment were used specimens compliant with EN ISO 6892-1:2009. Strength tests were conducted at room temperature using an MTS 322 computer-programmable, hydraulic test machine. For experiments axial extensometer were used with gauge length of $25 \mathrm{~mm}$. The applied rate of specimen displacement was $u_{t}=0.02 \mathrm{~mm} / \mathrm{s}$, which corresponds to an initial strain rate of $\varepsilon_{t}=0.00081 / \mathrm{s}$.

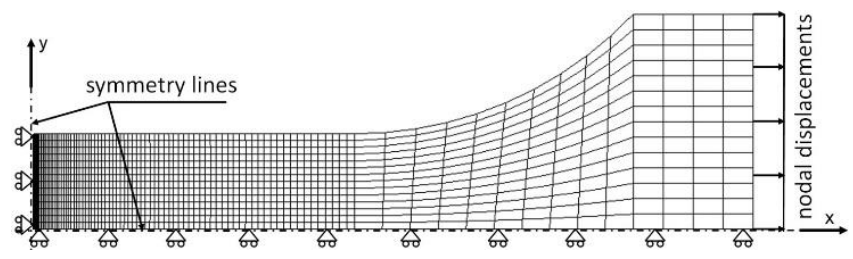

Fig. 1. Boundary conditions used for modeling of the tensile behavior of the axisymmetric model

In order to determine the true work hardening curve of the solid $316 \mathrm{~L}$ the hybrid method (experimental-numerical) was used (Derpeński and Seweryn, 2011). The curve was further used to define the plastic deformation behavior of sintered $316 \mathrm{~L}$ in the numerical models. The boundary conditions used in the calculations shown in Fig. 1. The calculations used an elastic-plastic material model with isotropic hardening. The value of Young's modulus $E_{s}=202 \mathrm{GPa}$ was determined empirically and Poisson's ratio was $v_{s}=0.3$. The received curve $\sigma_{e q}-\varepsilon_{e q}$ (Fig. 2a) defining the solid $316 \mathrm{~L}$ nonlinearity was obtained iteratively. A comparison of the numerical results and experiments is shown in Fig. $2 b$. 
a)

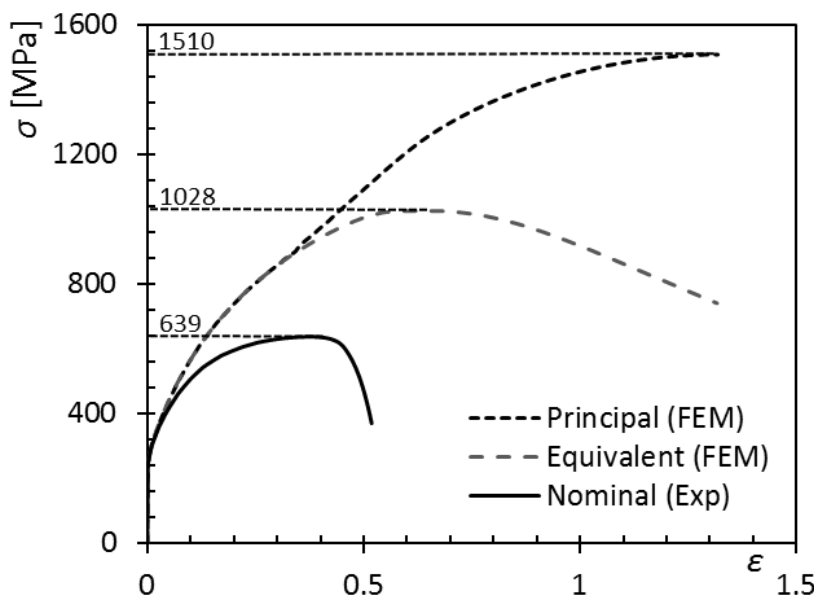

b)

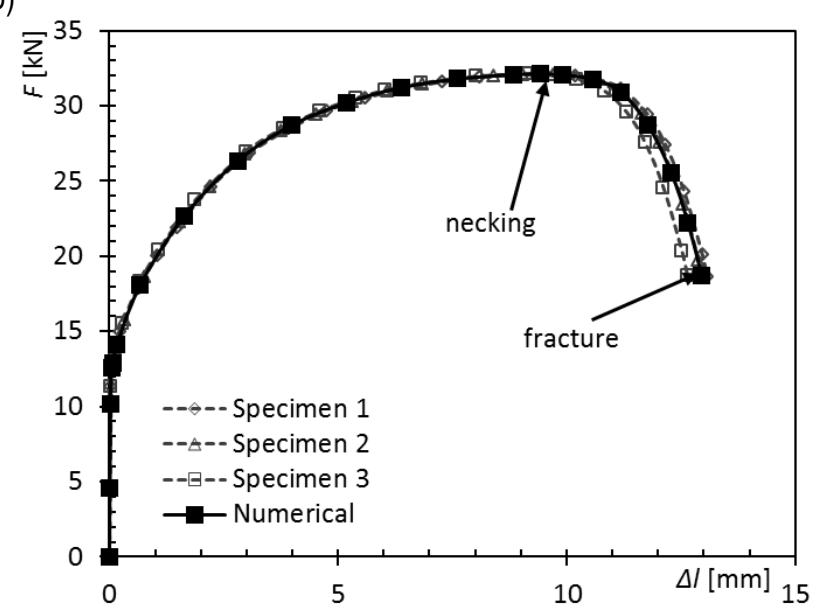

Fig. 2. Comparison of numerical and experimental curves of solid 316L: a) stress-strain, b) force-elongation

The critical force and elongation at which the fracture occurs is determined at the moment when the stress $\sigma_{1}$ has reached the maximum, critical value $\sigma_{c}=1510 \mathrm{MPa}$ (Fig. 3).

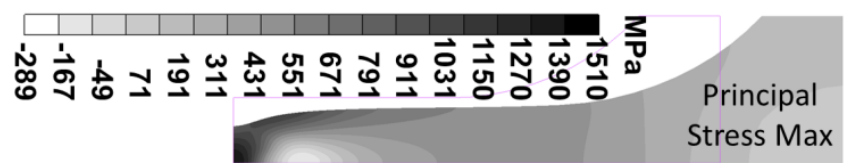

Fig. 3. Distributions of principal stress $\sigma_{1}$ at the initial fracture moment

\section{NUMERICAL MODELING OF THE TENSION AND COMPRESSION BEHAVIOR OF THE POROUS 316L}

For the investigation 3 samples were obtained with porosities of 41,33 and $26 \%$ using an average pressing pressure of 200 , 400 and $600 \mathrm{MPa}$ respectively. In order to take into account the shapes of porous mesostructures in numerical calculations, the microtomography was used. The microtomographic images were obtained by the SkyScan 1172 high resolution micro-CT which is located at the Faculty of Materials Science and Engineering, Warsaw University of Technology. The procedure of mapping three-dimensional porous structures using micro-CT is shown in Fig. 4. Three porous models were separated with the dimensions $0.45 \times 0.2 \times 0.6 \mathrm{~mm}$, one for each of the porosities. The 3D geometric models were created using Materialise Mimics software.

For the numerical modeling, MSC.Marc software based on finite element method (FEM) was used. In the calculations were used Tetra 134 tetrahedral isoparametric 4-node finite elements (Marc® 2010, Product Documentation). For modeling of the tensile and compression behavior of the porous materials the boundary conditions based on nodal displacements and contact were used (Fig. 5). Application of the fixed displacements in appropriate directions define the symmetry conditions. To modeling of the compression behavior were used two approaches (compression I and II). The first approach was applied for macroscopic deformation $\varepsilon \leq 0.1$ because further deformation causes a distortions of meshes which are inconsistent with the physical process of compression. In compression I and II, self-contact was applied in order to take into account the effect of closing the pores. For models used in compression II added bases and rigid contact surfaces which prevent improper distortions such as in the case of compression I. Coulomb model was used to modeling of friction in contact. The calculations used the elastic-plastic material model using the Huber-von Mises plasticity yield criteria. Young's modulus $E_{s}=202 \mathrm{GPa}$ and Poisson's ratio $v_{s}=0.3$ determined experimentally were assumed. The material nonlinearity was determined by the curve $\sigma_{e q}-\varepsilon_{e q}$ (Fig. 2a).

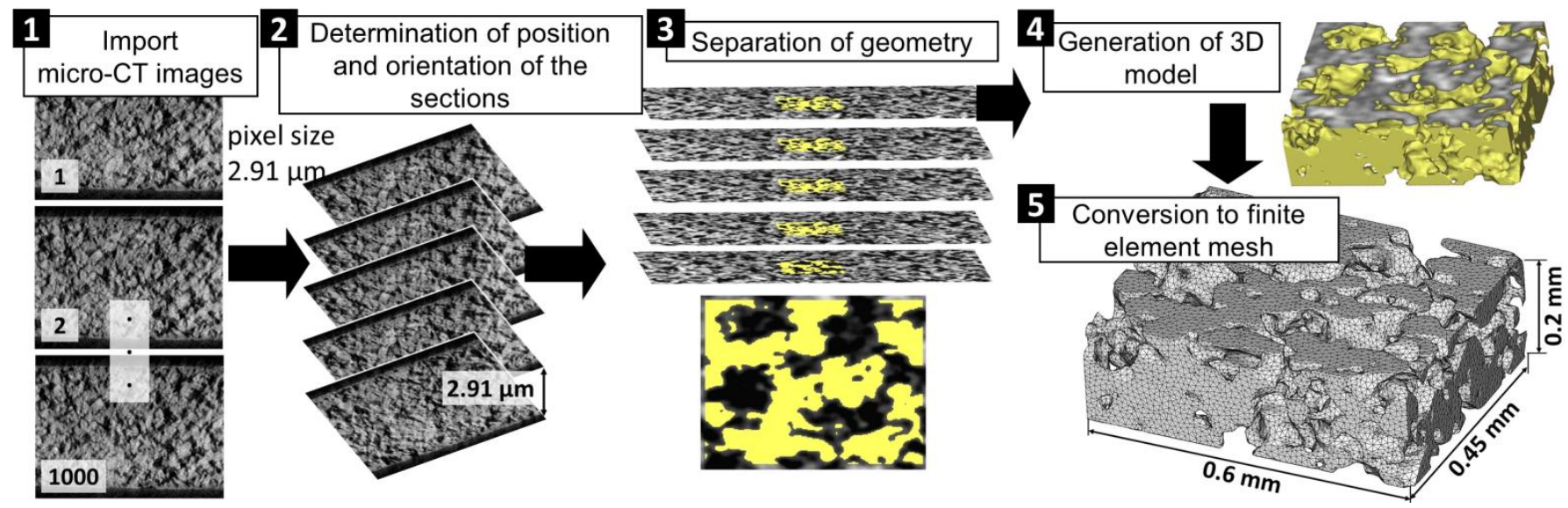

Fig. 4. The procedure of mapping 3D porous structures using micro-CT 


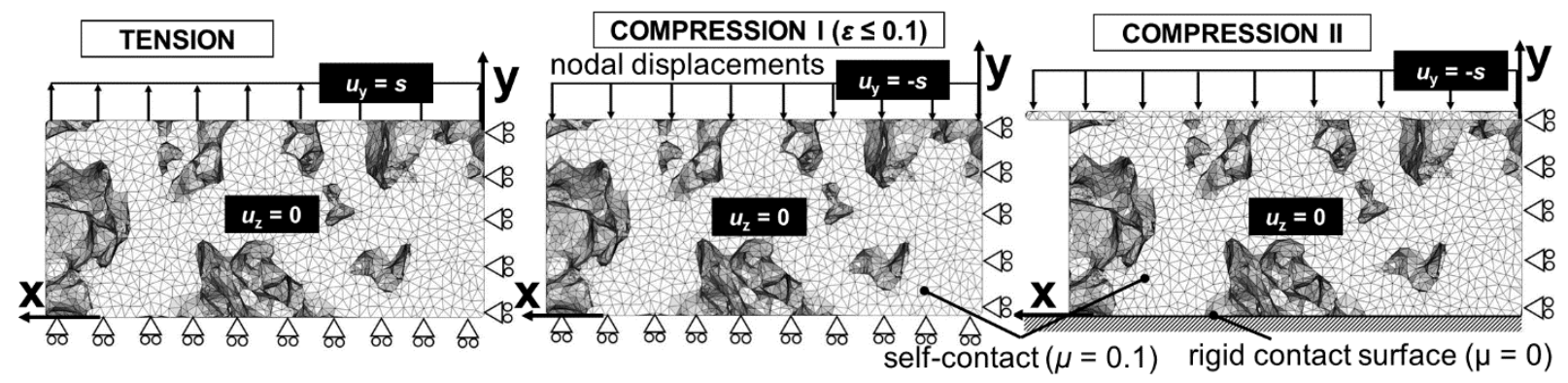

Fig. 5. The boundary conditions used for modeling of the tension and compression of sintered $316 \mathrm{~L}$

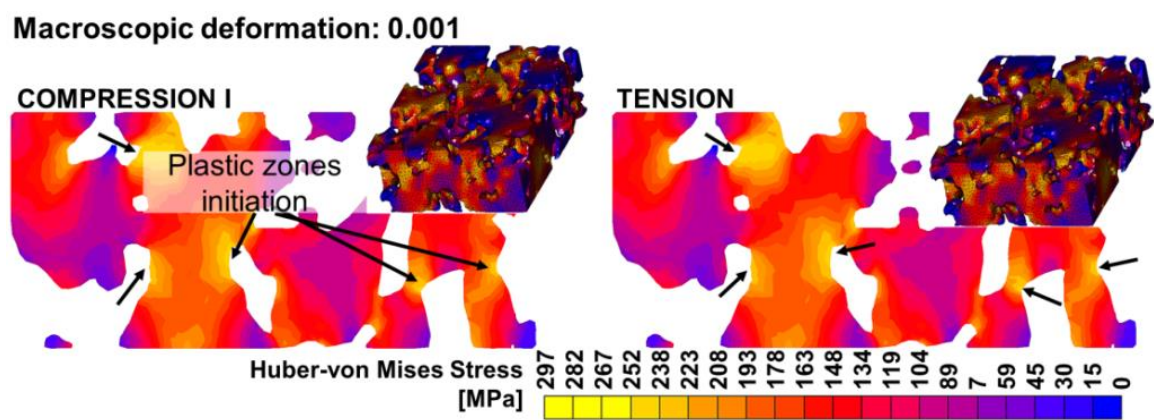

Fig. 6. Huber-von Mises Stress distributions indicating plastic zones initiation

\section{NUMERICAL RESULTS}

To indicate the plastic zones initiation, Huber-von Mises stress distributions were used in models deformed in $0.1 \%$. Plastic zones initiation are localized in notches in the pores shape. An example of the stress distributions in the sinter with the $41 \%$ of porosity shown in Fig. 6. Fig. 6 shows similarity between stress distributions obtained for the tension and compression in small strain (macroscopic) range. This is due to the solid $316 \mathrm{~L}$ deformation process in small strain range, where tensile and compressive stress values are equal.

Because of not taking into account the fracture criteria in the calculations, critical strain $\varepsilon c$ (macroscopic nominal strain) at the macro fracture in tension was determined on the basis of experimental results (Falkowska and Seweryn, 2015). In the investigation it was assumed that crack initiation in the material occurs at the maximum principal stress value $\sigma_{c}=1510 \mathrm{MPa}$, received experimentally for solid 316L (Fig. 2a). Principal stress $\sigma 1$ distributions at the macro fracture moment shown in Fig. 7. Locations where have been achieved stress values close to the critical $\sigma_{c}$ were indicated using arrows. Areas of crack initiation are localized in notches in the pores shape as in the case of plasticity initiation.
In Fig. 8 is shown comparison of the principal stress distributions obtained using two approaches of compression (I and II) when macroscopic strain $\varepsilon=0.1$. As seen the stress distributions are similar to each other. This means that the both methods may be used alternatively up to $10 \%$ of macroscopic strain. Deformation larger than $10 \%$ using the method of compression I causes a distortions of meshes (Fig. 9). Principal stress distributions in sinters with porosity of $41 \%$ and $26 \%$, deformed in 20,30 and $40 \%$, obtained using compression II shown in Fig. 10. Locations where compressive stresses reach the highest values are bridges with the smallest cross sections and notches in the shape of the pores.

Based on the stress and strain fields, the mechanism of macroscopic deformation was investigated. The influence of material discontinuities at the mesoscopic scale on macromechanical properties of the sintered materials describes nominal stressstrain curves shown in Fig. 11. The presented results indicate that value of porosity it is crucial factor which determine the tension and compresssion behavior of the porous materials. The mechanical properties decrease with the increase in porosity. It should be noted that there is high compliance between the results obtained by both methods used for compression modeling.

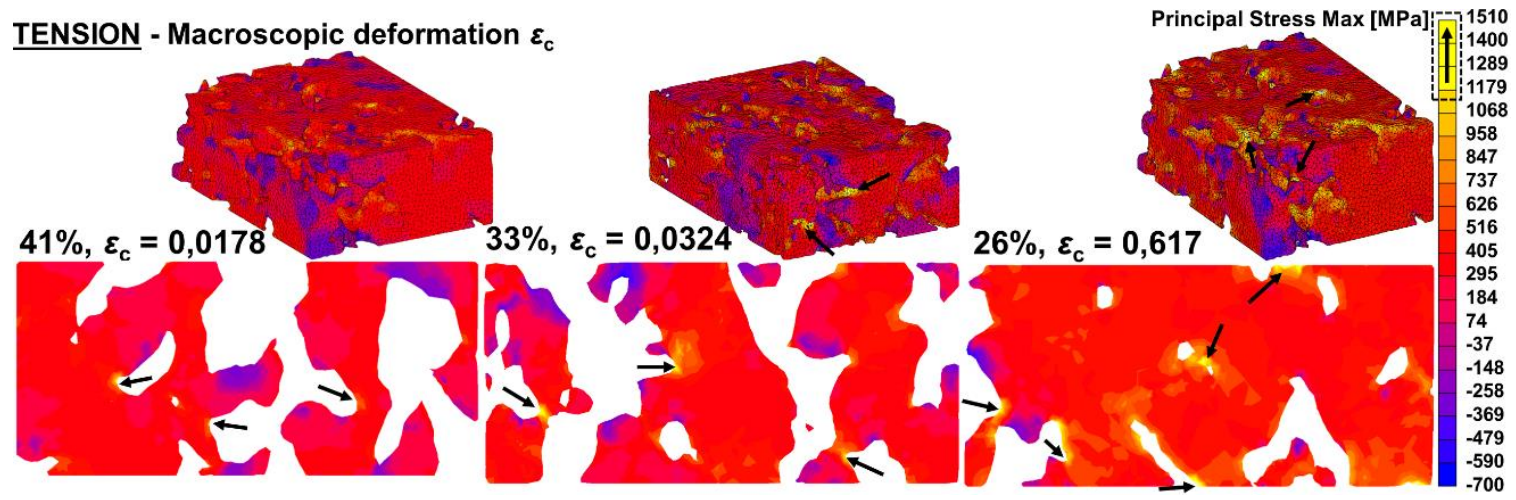

Fig. 7. Principal stress $\sigma_{1}$ distributions at the critical strain moment $\varepsilon_{c}$ 


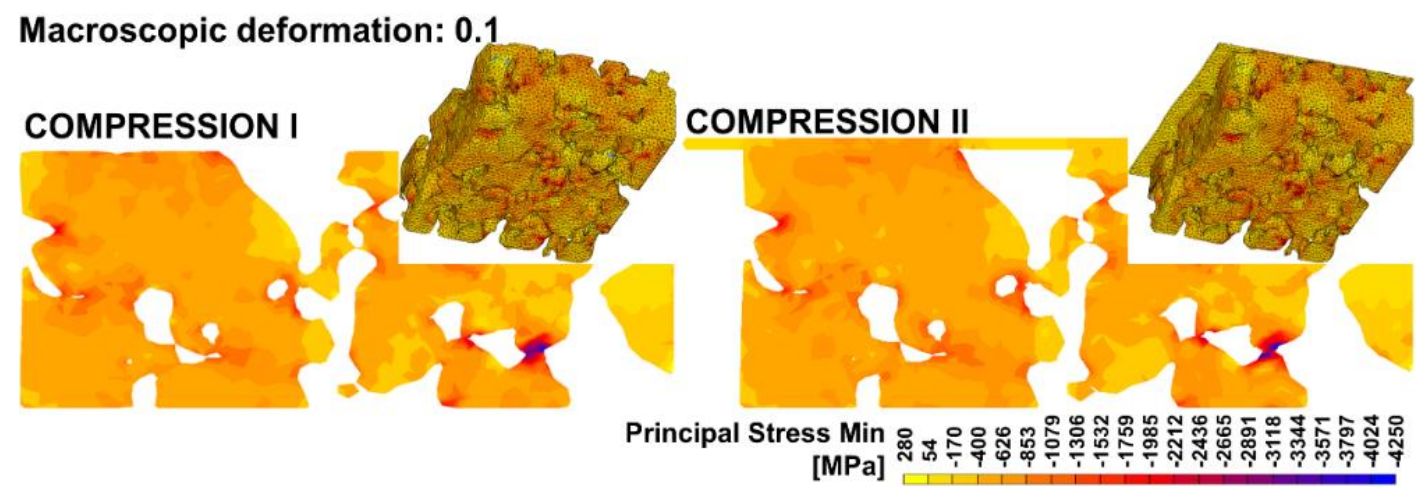

Fig. 8. Huber-von Mises Stress distributions indicating plastic zones initiation

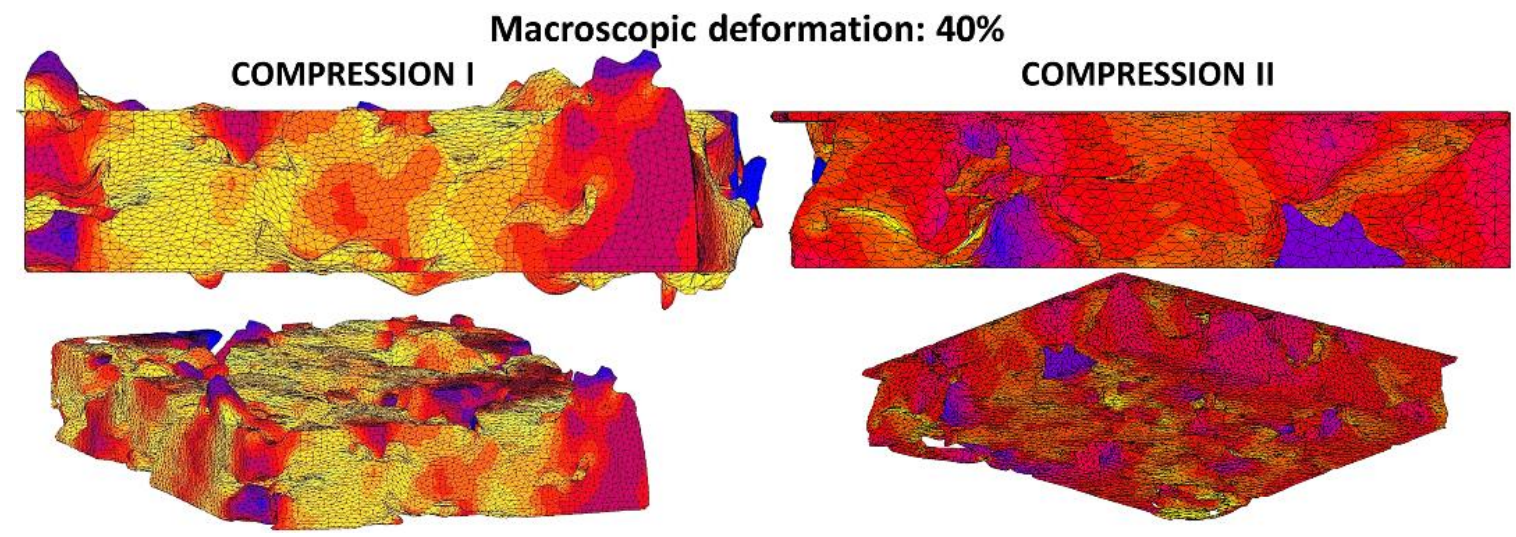

Fig. 9. Huber-von Mises Stress distributions indicating plastic zones initiation

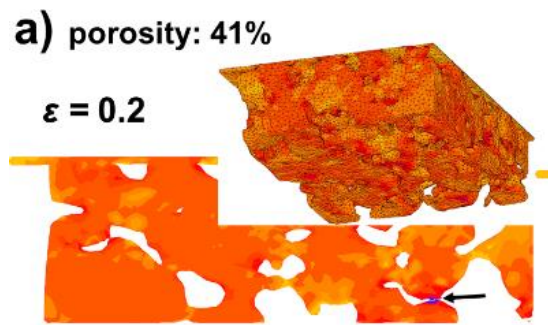

b) porosity: $26 \%$

\section{COMPRESSION II}

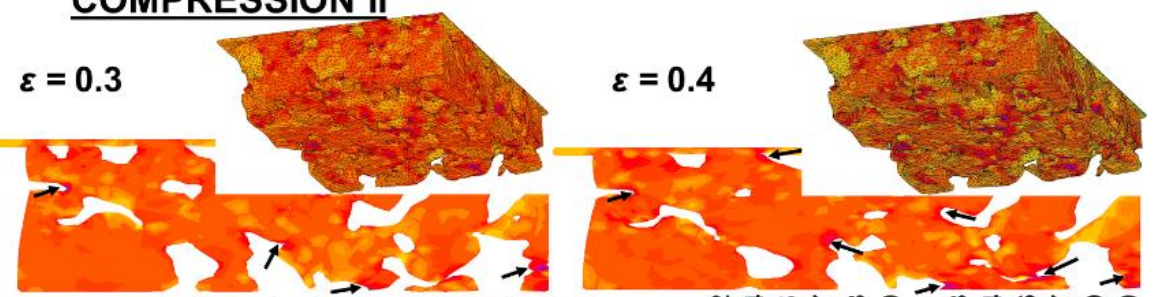

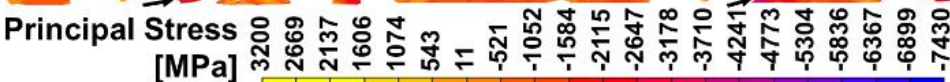

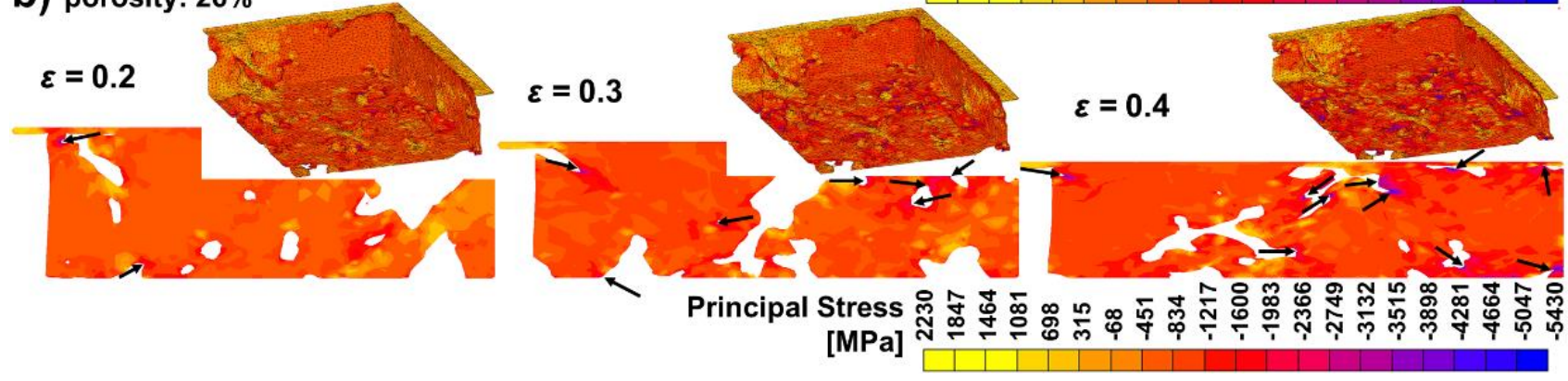

Fig. 10. Principal stress distributions obtained using compression II for porous $316 \mathrm{~L}$ with porosity of: a) $41 \%$, b) $26 \%$ 


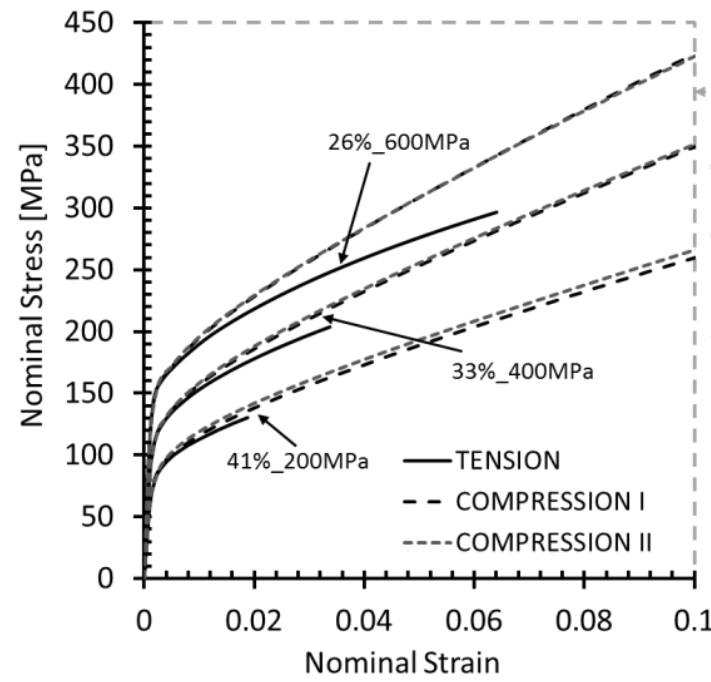

Fig. 11. Nominal stress-strain curves obtained for the sintered $316 \mathrm{~L}$

\section{CONCLUSIONS}

The paper presents modeling of the tensile and compression behavior of sintered $316 \mathrm{~L}$ with a porosity of 41,33 and $26 \%$, taking into account the pore shapes at the mesoscale.

The macromechanical properties of the sinters depends on the stress values in the bridges which connect the mesostructures. The deformation mechanism have reflection in the received hardening curves and showing an increase in values of Young's modulus, yield strength and ultimate strength with decreasing porosity. The presented results can be useful in design process of external and internal fixators to decribe the macroscopic nonlinearity of sintered $316 \mathrm{~L}$.

Due to the insufficient micro-CT accuracy, an important issue is research on methods which reduce the impact of the nonmapped geometries on mechanical properties of the materials. One of such method was proposed by Veyhl C. et al. (2013). Its application to the model described in this paper will be the subject of future research.

Taking into account the stress concentration in bridges of the mesostructures, an important issue is to model the damage accumulation process and cracking at these locations.

\section{REFERENCES}

1. Disegi J. A., Eschbach L. (2000), Stainless steel in bone surgery, Injury, 31,S-D2-6.

2. Ashby M. F., Evans A. G., Fleck N. A., Gibson L. J., Hutchinson J. W., Wadley H. N. G. (2000), Metal Foams: A Design Guid, Oxford: Butterworth-Heinemann.

3. Rammerstorfer F. G., Daxner T., Bohm H. J. (2002), Modeling and Simulation. In: Degischer HP, Kriszt B, editors. Handbook of Cellular Metals: Production, Processing Applications, Germany: Wiley-VCH.

4. Kujime T., Tane M., Hyun S. K., Nakajima H. (2007), Threedimensional image-based modeling of lotus-type porous carbon steel and simulation of its mechanical behaviour by finite element method, Materials Science and Engineering A, 460-461, 220-226.

5. Maruyama B., Spowart J. E., Hooper D. J., Mullens H. M., Druma A. M., Druma C., Alam M. K. (2006), A new technique for obtaining three-dimensional structures in pitch-based carbon foams. Scripta Materialia, 54, 1709-1713.

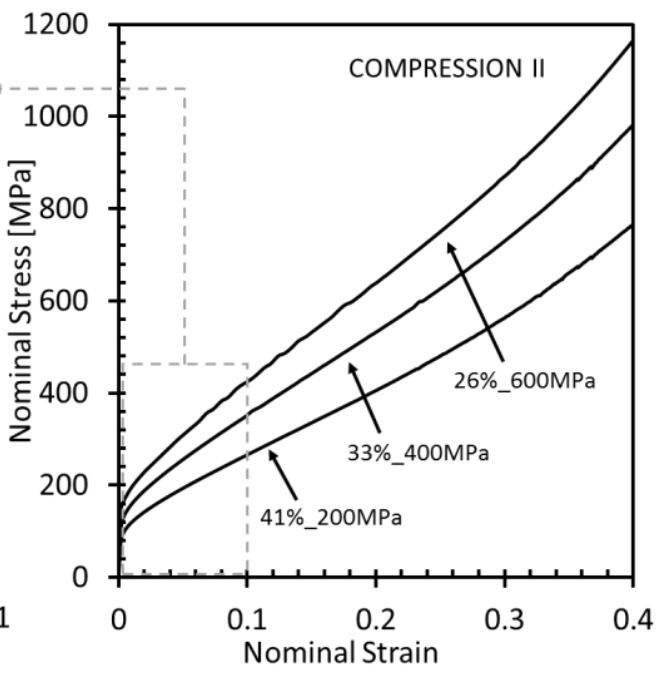

6. De Giorgi M., Carofalo A., Dattoma V., Nobile R., Palano F. (2010), Aluminium foams structural modelling, Computers \& Structures, 88, 25-35.

7. Marcadon V. (2011), Mechanical modelling of the creep behaviour of Hollow-Sphere Structures, Computational Materials Science, 50, 3005-3015.

8. Nammi S. K., Myler P., Edwards G. (2010), Finite element analysis of closed-cell aluminium foam under quasi-static loading. Materials and Design, 31, 712-722.

9. Michailidis N., Stergioudi F., Omar H., Tsipas D. N. (2010), An image-based reconstruction of the 3D geometry of an Al open-cell foam and FEM modeling of the material response, Mechanics of Materials, 42, 142-147.

10. Veyhl C., Belova I. V., Murch G. E., Fiedler T. (2011), Finite element analysis of the mechanical properties of cellular aluminium based on micro-computed tomography, Materials Science and Engineering A, 528, 4550-4555.

11. Michailidis N., Stergioudi F., Omar H., Tsipas D. (2010), FEM modeling of the response of porous Al in compression, Computational Materials Science, 48, 282-286.

12. Michailidis N. (2011) Strain rate dependent compression response of $\mathrm{Ni}$-foam investigated by experimental and FEM simulation methods, Materials Science and Engineering A, 528, 4204-4208.

13. Veyhl C., Fiedler T., Jehring U., Andersen U., Bernthaler T., Belova I. V., Murch G.E. (2013), On mechanical properties of sintered metallic fibre structures, Materials Science and Engineering A, 562, 83-88.

14. EN ISO 6892-1:2009, Metallic materials - Tensile testing - Part 1: Method of test at room temperature, CEN: 2009.

15. Derpeński Ł., Seweryn A. (2011), Experimental Research into Fracture of EN-AW 2024 and EW-AW 2007 Aluminum Alloy Specimens with Notches Subjected to Tension, Experimental Mechanics, 51, 1075-1094.

16. Marc® 2010, Product Documentation, Volume B: Element Library.

17. Falkowska A., Seweryn A. (2015), Fatigue of sintered porous materials based on $316 \mathrm{l}$ stainless steel under uniaxial loading. Materials Science (in press).

The paper has been accomplished under the research project No. S/WM/1/2013 financed by the Bialystok University of Technology. $\mathrm{M}$. Doroszko is a beneficiary of the project 'Scholarships for PhD students of Podlaskie Voivodeship'. The project is co-financed by European Social Fund, Polish Government and Podlaskie Voivodeship. 